\title{
Physical Activity and Sedentary Behaviour as Predictors of Adolescent Health in Rural and Urban Environments in Poland
}

Authors' contribution:

A) conception and design of the study

B) acquisition of data

C) analysis and interpretation of data

D) manuscript preparation

E) obtaining funding

\author{
Izabela Tabak $^{\mathrm{ACD}}$, Anna Oblacińska ${ }^{\mathrm{CD}}$, \\ Maria Jodkowska ${ }^{\mathrm{CD}}$ \\ Institute of Mother and Child in Warsaw, Poland
}

ABSTRACT

While numerous studies have examined correlates of physical activity, less attention has been given to identifying the rural/urban differences in the strength of the relationship between physical activity and health. The main objective of the current study was to analyze relationships between physical activity, sedentary behavior, and the health of rural and urban adolescents. Cross-sectional data on physical activity (Moderate-to-Vigorous Physical Activity, MVPA), sedentary behavior (watching TV and using a computer), self-rated general health, and mental health (General Health Questionnaire, GHQ-12) was assessed through a questionnaire in the sample of 600 Polish adolescents aged 13 years. Pearson $\chi^{2}$, t-Student tests and hierarchical regression analyses were used to compare differences by place of residence. No rural/urban differences in physical activity levels and self-rated health were found. Rural boys spent more time watching TV and urban adolescent males spent more time using a computer. Urban girls were more affected by stress than rural. Physical activity was an important predictor of self-assessed health (8\% of variance) and mental health (4\% of variance) of adolescents living in rural areas. The results show that physical activity level is an important predictor of rural adolescents' health and particular attention must be paid to promoting physical activities in rural environments.

KEYWORDS $\quad$ physical activity; sedentary behavior; adolescence; rural health

\section{Introduction}

Lifestyle and healthy behavior are direct factors that determine human health. Deficiencies in healthy behavior (especially physical activity), as well prevalence of risky health behaviors (such as the use of psychoactive substances) are the main causes of disorders in the periods of adolescence and the later years of life (Santrock 2007). For this reason, a lot of research is conducted into healthy behavior and its codependency with both physical and mental health (Conner and Norman 2005, Currie et al. 2008). However, very little research analyzes the difference between healthy behavior and the health of young people in rural and urban locations.

People living in rural areas tend to have higher levels of illness and disease risk factors than those in major cities. They do not always have the same opportunities for good health - they are generally disadvantaged in their access to goods, services, and educational opportunities. Rural residents confront 
additional access barriers such as transportation difficulties and a more restricted supply of medical services than residents of urban settings (Hartley et al. 1994). In Poland, the total urbanisation rate is 61\%, and poverty is strongly related to living in small towns or villages, particularly those in which large state-owned enterprises have been closed down (Mazut et al. 2009). The scale of deprivation can be analyzed not only in relation to healthcare, but also in access to sports and recreational facilities.

Physical activity is listed as one of the most important predictors of health for children, adolescents, and adults. Assessing one's own health as "very good" is in fact less common among teenagers who display a low level of physical activity (Harris et al 2006). For that reason, it is very important to describe both those factors which are conducive to practising physical exercises and those possible barriers which may hinder such activity (Biddle and Mutrie 2008). Sallis, Prochaska, and Taylor (2000) have classified the determinants of adolescents' physical activity into five categories: 1. Demographic /biological; 2. Psychological /cognitive /emotional; 3. Behavioral attributes / skills; 4. Social /cultural factors; and 5. Physical environment. Among the listed determinants, two groups of factors (socio-cultural and those connected with the physical environment) may specifically differ in the case of young people living in rural or urban environments. Participation in physical exercise is associated with the presence of suitable programs, facilities, and opportunities to exercise (Due et al. 2001), that can be more restricted for adolescents in rural environments.

The health benefits of physical activity for adults are well documented and regular participation in physical activities is known to make an important contribution to improving quality of life, both physical and psychological (Biddle and Mutrie 2008, Due et al. 2001, Sallis et al. 2000). The benefits of physical activity for young people are less well documented, but the positive effects on both physical and mental health have been confirmed in research over recent years (Biddle and Mutrie 2008, Due et al. 2001, Sallis et al. 2000). Between these benefits are healthy growth and development of cardiorespiratory system as well as the bones and muscles, improved fitness, strength, coordination, and reduction of anxiety, symptoms of depression, psychological distress, or sleep problems.

Activities which are the opposite to physical activity include watching television, and in recent years, computer use. These are linked with long hours of motionlessness, mainly in a sitting position, and are described with the common name of sedentary behaviors. These behaviors are mentioned very frequently, next to inadequate physical activity, as one of the determinants of obesity, being overweight (Crespo et al. 2001), and poor posture (Kratenova et al. 2007). Many authors have also drawn attention to the unhelpful influence which watching television and computer games have on the mental condition of young people, decreasing their creativity (American Academy of Pediatrics 2001).

The results of research from various countries concerning the incidence of differences in healthy behavior and the health of urban and rural children are not unambiguous. Some research shows that rural young people participate less in sport and physical activities than their urban counterparts (Mummery et al. 2000). Others show that urban children are more physically inactive than those in the countryside (Liu et al. 2008). Many studies also show gender differences in rural adolescents - girls are more inactive than boys (Prasad et al. 2009). Inconsistencies in the literature indicate that physical activity in adolescents in rural vs. urban settings is poorly understood.

The objectives of the present study were:

1. To examine the physical activity, sedentary behaviors, and health of adolescents in relation to their place of residence;

2. To analyze relationships between physical activity, sedentary behaviors, and the health of rural and urban adolescents. 


\section{Methods}

\section{Sample and procedures}

The sample consisted of 600 Polish adolescents aged 13.2 to 13.7 years who participated in a longitudinal study (Mikiel-Kostyra et al. 2002). The current study was a cross-sectional examination of a randomly selected subsample of a group of children born in Poland between 1 and 10 January 1995 (9,612 new-borns delivered on time and without chronic illnesses) whose mothers participated in a questionnaire survey three years later (1,250 children). The study was approved by the Bioethics Committee of Institute of Mother and Child in Warsaw (Opinion No 27/2007) and supported by the Polish Ministry of Science and Higher Education Project no N N404 329933.

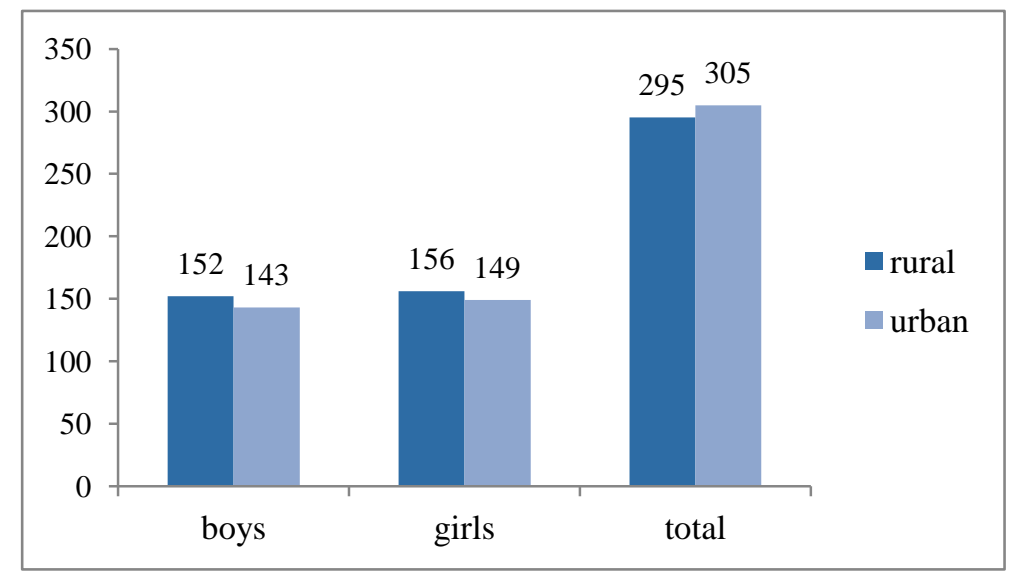

Questionnaires were posted to 1,177 adolescents, but the total number of questionnaires returned in this study was 638 (the response rate was 54\%). Due to missing data, 38 participants were excluded from study analysis, resulting in a total participant sample of 600 . Urban residents made up $49 \%$ of the subjects, and rural residents $51 \%$ (Figure 1).

Figure 1. Sample characteristics (number of participants)

\section{Measures}

The questionnaire survey used subjective indicators of health, based on self-assessment, in accordance with recommendations by the World Health Organisation (1996).

Physical activity. The screening devised by Prochaska, Sallis, and Long (2001) for use in primary healthcare for children was used as the indicator of physical activity. The standard for physical activity is the MVPA indicator (Moderate-to-Vigorous Physical Activity). The young people were asked to report the number of days over the past week that they had been physically active for at least 60 minutes per day. The question was preceded by an explanatory text that defined MVPA and gave examples of such activities.

Sedentary behaviors. The participants were asked how many hours per day they watched television (including videos and DVDs) and used a computer (for playing games, emailing, chatting or surfing the internet) in their spare time on weekdays and weekends. The total number of hours they spent during the week in front of a television or computer (screen time) was calculated based on these answers.

Self-rated health. Self-rated health is a subjective indicator of general health. It is found to be predictive of objective health outcomes in adults (Burnstroem and Fredlund 2001), and is a more appropriate measure of adolescent health than traditional morbidity and mortality measures (Currie et al. 2008). It's a relatively stable construct during adolescence, and deteriorates consistently with a lack of general well-being, disability, healthcare attendance, and health-compromising behavior (Breidablik et al. 2009). Young people were asked to describe their health ("Would you say your health is..."), with response options of 'excellent' (1), 'very good' (2), 'good' (3), 'fair' (4), and 'poor' (5).

Mental health. To assess mental health, the General Health Questionnaire (GHQ-12) developed by David Goldberg (1972) was applied. The GHQ exists in several forms, but the 12-item GHQ (GHQ-12) has recently become the most popular form of the scale because of its relatively convincing validity (Goldberg and Williams 1998) as well as its space-saving properties in survey studies. The GHQ-12 is a widely-used standard composite measure of psychological distress applicable to adolescents (Doyle 2003) as well as adults. The GHQ-12 consists of 12 questions on recent concentration abilities, sleeping patterns, self-esteem, stress, despair, depression, and confidence. Respondents were asked to categorise their experiences relative 
to their normal functioning. Answers to 12 questions were converted into dichotomised values ( 0 to 1 , in accordance with the GHQ scale), and then added up. The higher the value on the GHQ-12 scale, the higher the probability of mental health disorders. Results ranging from 3 to 12 were interpreted as showing psychological distress. Internal consistency of GHQ-12 for the current sample was 0.79 ( $\alpha$-Cronbach's).

\section{Statistical analyses}

$t$-Student tests were used to compare residence differences in the distributions of physical activity and sedentary behaviors; Pearson $\chi^{2}$ tests were used for residence differences in health indicators. Four hierarchical regression analyses for variables predicting adolescent health in rural and urban environments were performed. Two models were assessed for self-assessed general health and two for mental health. In all the analyses, in the first step gender was provided as a controlled variable, in the second step TV watching was added, in the third computer use, and in the last physical activity.

\section{Results}

\section{Physical activity and sedentary behaviors in rural and urban environments}

On average, adolescents were physically active 4.9 hours per week, they spent almost 18 hours/week watching TV (2.5 hours daily), and 13.4 hours/week (almost 2 hours daily) using a computer (table 1). No rural/urban differences in adolescents' physical activity levels were found. Rural/urban differences were statistically significant in computer use (urban adolescents were on the computer for a longer time than rural, $\mathrm{p}<0.001$ ) and for boys in watching TV (in rural areas they spent more time watching TV than their peers in towns, $\mathrm{p}=0.04)$.

Table 1. Physical activity and sedentary behaviors by gender and place of residence (mean hours/week)

\begin{tabular}{rccccccccc}
\hline & Total & $\begin{array}{c}\text { Total } \\
\text { Rural }\end{array}$ & Urban & Total & $\begin{array}{c}\text { Boys } \\
\text { Rural }\end{array}$ & Urban & Total & $\begin{array}{c}\text { Girls } \\
\text { Rural }\end{array}$ & Urban \\
\hline Physical activity & & & & & & & & & \\
M & 4.89 & 4.99 & 4.78 & 5.15 & 5.21 & 5.08 & 4.64 & 4.79 & 4.49 \\
SD & 1.8 & 1.8 & 1.9 & 1.8 & 1.8 & 1.9 & 1.8 & 1.7 & 1.9 \\
Watching TV & & & & & & & & & \\
M & 17.83 & 18.34 & 17.28 & 17.52 & $18.49^{*}$ & 16.36 & 18.18 & 18.19 & 18.17 \\
SD & 8.9 & 9.4 & 8.5 & 8.9 & 9.6 & 8.0 & 9.0 & 9.1 & 8.9 \\
Computer use & & & & & & & & & \\
M & 13.44 & $12.07^{* * *}$ & 14.88 & 14.85 & $13.91^{\dagger}$ & 15.84 & 12.06 & $10.26^{* * *}$ & 13.94 \\
SD & 9.3 & 8.5 & 9.9 & 9.4 & 9.1 & 9.7 & 8.9 & 7.5 & 9.9 \\
\hline
\end{tabular}

Note: differences rural/urban $t$-Student test: ${ }^{\dagger} p<0.1,{ }^{*} p<0.05,{ }^{* * *} p<0.001$

\section{Self-rated and mental health of adolescents in rural and urban settings}

Participants most often rated their general health as very good or good, in both rural and urban areas (see table 2). The percentage of girls affected by stress was twice as high in urban than in rural areas $(\mathrm{p}=$ 0.054). 
Table 2. General and mental health of adolescents by gender and place of residence (\%)

\begin{tabular}{|c|c|c|c|c|c|c|c|c|c|}
\hline & \multicolumn{3}{|c|}{ Total } & \multicolumn{3}{|c|}{ Boys } & \multicolumn{3}{|c|}{ Girls } \\
\hline & Total & Rural & Urban & Total & Rural & Urban & Total & Rural & Urban \\
\hline \multicolumn{10}{|l|}{ General health (self-rated) } \\
\hline excellent & 19.1 & 20.5 & 17.5 & 20.1 & 22.5 & 17.6 & 18.0 & 18.6 & 17.4 \\
\hline very good & 48.8 & 46.6 & 51.2 & 47.1 & 41.7 & 52.8 & 50.5 & 51.3 & 49.7 \\
\hline good & 25.8 & 26.4 & 25.1 & 26.3 & 29.1 & 23.2 & 25.2 & 23.7 & 26.8 \\
\hline fair or poor & 6.4 & 6.5 & 6.2 & 6.5 & 6.6 & 6.3 & 6.2 & 6.4 & 6.0 \\
\hline \multicolumn{10}{|l|}{ Mental health (GHQ-12) } \\
\hline good health (0-2) & 85.7 & 86.7 & 84.6 & 87.3 & 85.3 & 89.4 & 84.1 & 88.1 & 79.9 \\
\hline psychological distress (3-12) & 14.3 & 13.3 & 15.4 & 12.7 & 14.7 & 10.6 & 15.9 & $11.9^{\dagger}$ & 20.1 \\
\hline
\end{tabular}

Note: differences rural/urban $\chi^{2}$ test: ${ }^{\dagger} p<0.1$

\section{Regression analyses}

Regression analyses for adolescents living in rural areas showed that physical activity is an important predictor of both self-assessed health (8\% of variance, see table 3 ) and mental health (4\% of variance, see table 4). Relationships between these variables in urban areas were very weak. The relationships observed were stronger for boys than for girls. For rural boys, physical activity explained $11 \%$ of the self-assessed health variance (for rural girls $5 \%$ ) and $6 \%$ of the mental health variance (for girls $2 \%$ ).

Table 3. Summary of hierarchical regression analyses for variables predicting self-rating of adolescents in rural and urban settings

\begin{tabular}{|c|c|c|c|c|c|}
\hline Variable & $\mathbf{B}^{\mathbf{a}}$ & SE B ${ }^{a}$ & $\mathbf{B}^{\mathbf{a}}$ & $\mathbf{R}^{2}$ & $\Delta \mathbf{R}^{2}$ \\
\hline \multicolumn{6}{|c|}{ Self-rated health } \\
\hline \multicolumn{6}{|l|}{ Rural } \\
\hline Gender (Step 1) & .11 & .10 & .06 & .00 & .00 \\
\hline Watching TV (Step 2) & .00 & .01 & .01 & .00 & .00 \\
\hline Computer use (Step 3) & -.01 & .01 & -.04 & .00 & .00 \\
\hline Physical activity (Step 4) & -.14 & .03 & -.29 & .08 & $.08^{* * *}$ \\
\hline \multicolumn{6}{|l|}{ Urban } \\
\hline Gender (Step 1) & .03 & .09 & .02 & .00 & .00 \\
\hline Watching TV (Step 2) & -.00 & .01 & -.01 & .00 & .00 \\
\hline Computer use (Step 3) & -.01 & .01 & -.09 & .01 & .01 \\
\hline Physical activity (Step 4) & -.06 & .03 & -.14 & .02 & $.02 *$ \\
\hline
\end{tabular}

Note: ${ }^{a}$ Values in the Step $4 ; *^{*} p<0.05, * * * p<0.001$

Table 4. Summary of hierarchical regression analyses for variables predicting adolescent mental health in rural and urban settings

\begin{tabular}{|c|c|c|c|c|c|}
\hline Variable & $\mathbf{B}^{\mathbf{a}}$ & ${\text { SE } \mathbf{B}^{\mathrm{a}}}$ & $\boldsymbol{\beta}^{\mathbf{a}}$ & $\overline{\mathbf{R}^{2}}$ & $\Delta \mathbf{R}^{2}$ \\
\hline \multicolumn{6}{|c|}{ Mental health } \\
\hline \multicolumn{6}{|l|}{ Rural } \\
\hline Gender (Step 1) & .14 & .20 & .04 & .00 & .00 \\
\hline Watching TV (Step 2) & .00 & .01 & .01 & .00 & .00 \\
\hline Computer use (Step 3) & .00 & .01 & .01 & .00 & .00 \\
\hline Physical activity (Step 4) & -.20 & .06 & -.21 & .04 & $.04 * * *$ \\
\hline \multicolumn{6}{|l|}{ Urban } \\
\hline Gender (Step 1) & -.40 & .23 & -.11 & .01 & $.01^{\dagger}$ \\
\hline Watching TV (Step 2) & .02 & .01 & .08 & .02 & .01 \\
\hline Computer use (Step 3) & .00 & .01 & .01 & .02 & .00 \\
\hline Physical activity (Step 4) & .01 & .06 & .01 & .02 & .00 \\
\hline
\end{tabular}




\section{Discussion}

The current paper presents data on 600 Polish adolescents. The results show that the level of physical activity is an important predictor of rural adolescents' health. Analyses showed various levels of dependence between healthy behavior and the health of rural and urban young people. The strength of the study was the almost equal representation of rural vs. urban teens; the limitation was the use of exclusive subjective indicators of general health and physical activity (the data was all self-reported). However, use of subjective assessments was conducted in line of World Health Organization (1996) recommendations. This approach is especially helpful for evaluating the health of young people, as it permits a description of general and mental health from the perspective of the young themselves. Subjective evaluation of physical activity using the MVPA indicator is an increasingly frequently-used method in research, because of its important correlation with objective research (for example with the aid of an accelerometer) (Due et al. 2001).

The study suggested a presence of very slight differences between the health and healthy behavior of rural and urban young people. At the same time it showed that physical activity is a specifically important predictor of the health of rural young people. The results obtained should be an indicator that particular attention must be paid to promoting physical activities in rural environments.

Analyses concerning the diversity of how young people self-assess their general and mental health, measured with the aid of the GHQ-12 scale in a full sample, indicated that almost $70 \%$ of young people assessed their health as 'very good' or 'excellent', and over $80 \%$ reached results on the GHQ-12 scale confirming their good mental health, irrespective of sex or place of residence. Only analyses conducted in sub-groups indicated that rural girls showed somewhat less frequent feelings of psychological distress compared to urban girls. The results of the HBSC study among Polish 15-year-olds also indicated that rural youth showed a somewhat higher self-assessment of health than their urban counterparts (Mazur et al. 2007). Roher, Borders and Blanton (2005), for their part, highlight the lack of a town/country distinction regarding frequency of feelings of distress.

In accordance with Prochaska's (2001) recommendations, young people should be physically active for at least 60 minutes daily for at least 5 days of the week. The study showed that $60 \%$ of subjects meet these criteria, in both town and country. This result is significantly more positive than that obtained in the HBSC study in 2002 (Roberts et al. 2004). Currently, however, the need for daily physical activity, 7 days a week, is increasingly often discussed (Currie et al. 2008, Janssen and Leblanc 2010). Fewer than one-third of the subjects (35\% of boys and $20 \%$ of girls) met the criterion of daily physical activity, irrespective of place of residence. In the study, no important differences in the range of physical activities as linked to the place of residence were confirmed.

In accordance with the recommendations of the American Academy of Pediatrics (2001), young people should not spend more than 1 to 2 hours daily watching televisior ( $(\mathrm{h} / \mathrm{week}$ ), with regard both to the possible physical (including the risk of obesity) and psycho-social consequences (rise in aggression, frequency of use of psycho-active substances, lowered self-esteem). According to the results of our study, only $10 \%$ of teenagers spend no more than 1 hour a day watching television; the average time young people spend watching TV is 2 hours 30 minutes daily. The average time spent in front of a computer is almost 2 hours daily, and urban youth spend almost half an hour more using computers than those in the countryside. The frequency of computer use by girls was significantly less in the countryside than in the town, and the frequency of TV watching was greater in rural boys than urban ones. The less frequent use of computers by rural youth may to a considerable degree result from rural the Polish youth's relative lack of access to computers. More frequent TV watching may, for its part, be linked to less access to other forms of entertainment in the rural environment. American research shows that overweight rural children are more likely than their metropolitan counterparts to use both a computer and television (Lutfiyya et al. 2007).

Research has often confirmed the positive association between physical activity and health indicated (Abu-Omar et al. 2008, Barros et al. 2009, Hamer et al. 2009, Hong et al. 2009, Janssen and Leblanc 2010, Page and Suwanteerangkul 2009). However, a clear distinction has been noted between town and 
countryside in the strength of the link between physical activity and the health of young people. The level of physical activity appeared to be a much stronger predictor of health (both general and mental) of rural young people than it did of urban youth. This means that activities to promote health in rural areas should of necessity help to raise the level of physical activity. Results from other studies indicate that even modest amounts of physical activity can have health benefits in high-risk youngsters and the dose-response relationships indicate that the more physical activity, the greater the health benefit (Janssen and Leblanc 2010). International research confirms significant regional differences in relationships between psychical activity and health and the need to tailor school and public health efforts to the different regions (Iannotti et al. 2009).

The level of rural young people's physical activity may be raised by changing stereotypes, above all regarding rural girls low physical activity (Lee and Macdonald 2009), or by removing barriers such as the lack of availability of any sporting infrastructure (Due et al. 2001). Recreational facilities are less common in low-income neighborhoods than in higher-income ones (Romer 2005) and in rural than in urban communities. However, in rural communities youth sports may be particularly popular because of the few other social activities available (Findholt et al. 2010).

In recent years, more and more initiatives are being taken in different countries to increase youth physical activity. Not all are successful, like school-based interventions (Elder et al. 2011) or improvements to parks (Cohen et al. 2009) in southern California. However, review of school-based programs show the reasonableness and appropriateness of taking action to increase physical activity (Ribeiro et al. 2010). Good results for increasing the physical activity of youths shows the Middle-School Physical Activity and Nutrition (M-SPAN) study (McKenzie et al 2004, Sallis et al 2003), SPARK (Sports, Play, and Active Recreation for Kids) programs for elementary and middle schools (Dowda et al. 2005, McKenzie et al. 2009), or Gold Medal Schools program (Jordan et al. 2008). The Healthy for Life program findings indicate that students significantly improved their self-esteem over the course of the school year with more physical activity (Prosper et al. 2009).

A new possibility to increase the physical activity level could be, surprisingly, the manipulation of young people's willingness to play computer games. As research shows, when given free choice, children spend more than half of their available time participating in interactive versions of computer games (Sit at al. 2010). These versions of games provide significantly more moderate-to-vigorous physical activity and greater energy expenditure than the computer screen versions. An important construct among the physical environmental correlates of physical activity, analyzed in latest journal publications, is also neighborhood "walkability". In Belgian studies it was related to accelerometer-based physical activity among adolescents living in low-SES neighborhoods (De Meester et al. 2012). This indicates the need for environmental changes, especially in poor communities.

An answer to this environmental need is a program currently being implemented in Poland, the 'My sports field - Orlik 2012' officially initiated in November 2007. This program was developed to construct easy-access, free-of-charge sports fields in each community to promote active lifestyles. New sports facilities are being developed to promote sustainable physical development for children from small communities and more disadvantaged areas such as rural settings. A typical Orlik sports complex includes two sports fields, one for soccer and one for other uses. By the end of 2011, 2012 sports fields had been completed and opened for public use in Poland (http://orlik2012.pl). The program contributes to the reduction of social inequalities, ensuring equal access to sports and recreational facilities. Improvement across two important child health indicators was anticipated as a result: an increase in the level of physical activity and a reduction in the prevalence of injuries and related health consequences (Mazur et al. 2009).

Programs to promote participation need to address many factors: In the short term, there may be practical issues around the provision of facilities, transport, and finance; in the longer term, there is an issue of improving knowledge and modifying attitudes and beliefs about what physical activity is and its potential 
health benefits (Due et al. 2001). The Polish program is the first step towards improving the health of adolescents in rural areas.

\section{REFERENCES}

Abu-Omar, K. \& Rütten, A. (2008). Relation of leisure time, occupational, domestic, and commuting physical activity to health indicators in Europe. Prev Med, 47, 319-323. DOI: 10.1016/j.ypmed.2008.03.012.

American Academy of Pediatrics (2001). Children, adolescents, and television. Pediatrics, 107, 423-426. DOI: 10.1542/peds.107.2.423.

Barros, M.B., Zanchetta, L.M., Moura, E.C. \& Malta, D.C. (2009). Self-rated health and associated factors, Brazil, 2006. Rev Saude Publica, 43, 27-37. http://dx.DOI.org/10.1590/S0034-89102009000900005.

Biddle, S. \& Mutrie, N. (2008). Psychology of physical activity. London: Routledge.

Breidablik, H.J., Meland, E. \& Lydersen, S. (2009). Self-rated health during adolescence: stability and predictors of change (Young-HUNT study, Norway). Eur J Public Health, 19, 73-78. DOI: 10.1093/eurpub/ckn111.

Burnstroem, B. \& Fredlund, P. (2001). Self-rated health: is it a good predictor of subsequent mortality among adults in lower as well as higher social classes? J Epidemiol Community Health, 55, 836-840.

Cohen, D., Golinelli, D., Williamson, S., Sehgal, A., Marsh, T. McKenzie, T.L. (2009). Effects of park improvements on park use and physical activity policy and programming implications. Am J Prev Med., 2009 December; 37(6), 475. DOI: 10.1016/j.amepre.2009.07.017.

Conner, M. \& Norman, P. (2005). Predicting health behaviour. England: Open University Press.

Crespo, C., Smit, E., Troiano, R., Bartlett, S., Macera, C. \& Andersen, R. (2001). Television watching, energy intake and obesity in US children. Arch Pediatr Adolesc Med, 155, 360-365.

Currie, C., Nic Gabhainn, S., Godeau, E., et al. (2008). Inequalities in young people's health: HBSC international report from the 2005/2006 Survey. Copenhagen: WHO Regional Office for Europe (Health Policy for Children and Adolescents, No. 5).

De Meester, F., Van Dyck, D., De Bourdeaudhuij, I., Deforche, B., Sallis, J.F. \& Cardon, G. (2012). Active living neighborhoods: is neighborhood walkability a key element for Belgian adolescents? BMC Public Health, 4, 12, 7. Retrieved April 4, 2012, from http://www.biomedcentral.com. DOI: 10.1186/1471-2458-12-7

Dowda, M., Sallis J.F., McKenzie T.L., Rosengard, P. \& Kohl, H.W. (2005). Evaluating the sustainability of SPARK physical education: a case study of translating research into practice. Research Quarterly for Exercise and Sport, 76, 11-19.

Doyle, M. (2003). Health status. In K. Sproston \& P. Primatesta (Eds.), Health Survey for England 2002 Vol. 1: The health of children and young people. London: The Stationery Office.

Due, P., Hickman, M., Komkow, A., et al. (2001). Physical activity. In C. Currie, O. Samdal \& W. Boyce (Eds.), Health Behaviour in School-aged Children Study: a World Health Organization Cross-National Study. Research Protocol for the 2001/2002 Survey (pp. 59-78). Scotland: University of Edinburgh.

Elder, J.P, McKenzie, T.L., Arredondo, E.M., Crespo, N.C. \& Ayala, G.X. (2011). Effects of a Multi-Pronged Intervention on Children's Activity Levels at Recess: The Aventuras para Niños Study. Adv. Nutr, 2, 171-176, DOI: 10.3945/an.111.000380

Findholt, N.E., Michael, Y.L., Davis, M.M. \& Brogoitti, V.W. (2010) Environmental influences on children’s physical activity and diets in rural Oregon: results of a youth photovoice project. Online Journal of Rural Nursing and Health Care, 10(2), 11-20. Retrieved April 4, 2012, from http://www.rno.org

Goldberg, D.P. (1972). The detection of psychiatric illness by questionnaire (Maudsley Monograph No. 21). England: Oxford University Press.

Goldberg, D.P. \& Williams, P. (1988). A user's guide to the General Health Questionnaire. London: NFER-Nelson.

Hamer, M., Stamatakis, E. \& Steptoe, A. (2009). Dose-response relationship between physical activity and mental health: the Scottish Health Survey. Br J Sports Med, 43, 1111-1114. DOI: 10.1136/bjsm.2008.046243.

Harris, K.M., Gordon-Larsen, P., Chantala, K. \& Udry, J.R. (2006). Longitudinal trends in race/ethnic disparities in leading health indicators from adolescents to young adulthood. Arch Pediatr Adolesc Med, 160, 74-78.

Hartley, D., Quam, L. \& Lurie, N. (1994). Urban and rural differences in health insurance and access to care. J Rural Health, 10, 98-108. 
Hong, X., Li, J., Xu, F., et al. (2009), Physical activity inversely associated with the presence of depression among urban adolescents in regional China. BMC Public Health, 9, 148. DOI: 10.1186/1471-2458-9-148.

Iannotti, R.J., Janssen, I., Haug, E., Kololo, H., Annaheim, B. \& Borraccino, A. \& the HBSC Physical Activity Focus Group (2009). Interrelationships of adolescent physical activity, screen-based sedentary behaviour, and social and psychological health. Int J Public Health, 54(Suppl 2), 191-198. DOI: 10.1007/s00038-009-5410-z.

Janssen, I., Leblanc, A.G. (2010). Systematic review of the health benefits of physical activity and fitness in schoolaged children and youth. Int $J$ Behav Nutr Phys Act, 7, 40-56.

Jordan, K.C., Erickson, E.D., Cox, R., Carlson, E.C., Heap, E., Friedrichs, M.,Moyer-Mileur, L.J., Shen, S. \& Mihalopoulosn, N.I. (2008). Evaluation of the Gold Medal Schools Program. J Am Diet Assoc., 108, 1916-1920. DOI: 10.1016/j.jada.2008.08.002.

Kratenova, J., Zejglicova, K., Maly, M. \& Filipova, V. (2007). Prevalence and risk factors of poor posture in school children in the Czech Republic. J Sch Health, 77, 131-137. DOI:10.1111/j.1746-1561.2007.00182.x.

Lee, J. \& Macdonald, D. (2009). Rural young people and physical activity: understanding participation through social theory. Sociol Health Illn, 31, 360-374. DOI:10.1111/j.1467-9566.2008.01138.x.

Liu, J., Bennett, K., Harun, N. \& Probst, J. (2008). Urban-rural differences in overweight status and physical inactivity among US children aged 10-17 years. J Rural Health, 24, 407-415. DOI:10.1111/j.1748-0361.2008.00188.x.

Lutfiyya, M.N, Lipsky, M.S., Wisdom-Behounek, J. \& Inpanbutr-Martinkus M. (2007). Is rural residency a risk factor for overweight and obesity for U.S. children? Obesity, 15, 2348-2356.

Mazur, J., Woynarowska, B., Hanke, W., et al. (2009). Poland: progress in child and adolescent physical activity promotion and injury prevention. In Socio-environmentally determined health inequities among children and adolescents (pp. 157-170). Denmark: WHO.

Mazur, J., Woynarowska, B. \& Kololo, H. (2007). Family socio-economic status and local area deprivation as determinants of self-perceived health and life style in Polish 15-year-old students. Warsaw: Institute of Mother and Child.

McKenzie, T.L., Sallis, J.F., Prochaska, J.J., Conway, T.L., Marshall, S.J. \& Rosengard, P. (2004). Evaluation of a twoyear middle-school physical education intervention: M-SPAN. Med. Sci. Sports Exerc., 36(8), 1382-1388.

McKenzie, T.L., Sallis, J.F. \& Rosengard, P. (2009). Beyond the Stucco Tower: design, development, and dissemination of the SPARK physical education programs. Quest, 61, 114-127.

Mikiel-Kostyra, K., Mazur, J. \& Bołtruszko, I. (2002). Effect of early skin-to-skin contact after delivery on duration of breastfeeding: a prospective cohort study. Acta Pcediatr, 91, 1301-1306. DOI: 10.1111/j.1651-2227.2002.tb02824.x.

Mummery, W.K., Schofield, G.M. \& Soper, L. (2000). Correlates of Adolescent Physical Activity in Regional Australia: Results from the Central Queensland Adolescent Physical Activity and Nutrition Study, AIESEP World Congress Proceedings. Rockhampton, Australia: Central Queensland University.

Page, R.M. \& Suwanteerangkul, J. (2009). Self-rated health, psychosocial functioning, and health-related behavior among Thai adolescents. Pediatr Int, 51, 120-125. DOI: 10.1111/j.1442-200X.2008.02660.x.

Prasad, A., St-Hilaire, S., Wong, M., Peterson, T. \& Loftin, J. (2009). Physical activity and depressive symptoms in rural adolescents. N Am J Psychol, 11, 173-188.

Prochaska, J.J., Sallis, J.F. \& Long, B. (2001). A physical activity screening measure for use with adolescents in primary care. Arch Pediatr Adolesc Med, 155, 554-559.

Prosper, MH, Moczulski, V.L., Qureshi, A., Weiss,M, \& Bryars, T.L. (2009). Healthy for Life/PE4ME: Assessing an Intervention Targeting Childhood Obesity. Californian Journal of Health Promotion, 7, Special Issue (Obesity Prevention), 23-32. Retrieved April 4, 2012, from http://www.cjhp.org

Ribeiro, I.C., Parra, D.C., Hoehner, C.M., Soares, J., Torres, A., Pratt, M., Legetic, B., Malta, D.C., Matsudo, V., Ramos, L.R., Simoes E.J. \& Brownson, R.C. (2010). School-based physical education programs: evidence-based physical activity interventions for youth in Latin America Global Health Promotion, 17(2), 05-15. DOI: 10.1177/1757975910365231.

Roberts, C., Tynjälä, J. \& Komkov, A. (2004). Physical activity. In C. Currie, C. Roberts, A. Morgan et al. (Eds.), Young people's health in context. Health Behaviour in School-aged Children (HBSC) Study: International Report from the 2001/2002 Survey (pp. 90-97). Denmark: WHO.

Rohrer, J., Borders, T. \& Blanton, J. (2005). Rural residence is not a risk factor for frequent mental distress: a behavioral risk factor surveillance survey. BMC Public Health, 5, 46. DOI: 10.1186/1471-2458-5-46. 
Romero, A.J. (2005). Low-income neighborhood barriers and resources for adolescents' physical activity. Journal of Adolescent Health, 36(3), 253-259.

Sallis, J.F., McKenzie, T.L., Conway, T.L., Elder, J.P., Prochaska, J.J., Brown, M., Zive, M.M., Marshall, S.J. \& Alcaraz, J.E. (2003). Environmental interventions for eating and physical activity a randomized controlled trial in middle schools. Am J Prev Med, 24(3), 209-217. DOI: 10.1016/S0749-3797(02)00646-3

Sallis, J., Prochaska, J. \& Taylor, W. (2000). A review of correlates of physical activity of children and adolescents. Med Sci Sports Exerc, 32, 963-975.

Santrock, J. (2007). Adolescence. New York: McGraw-Hill.

Sit, C.H.P., Lam, J.W.K. \& McKenzie, T.L. (2010). Children's use of electronic games: choices of game mode and challenge levels. International Journal of Pediatrics, 2010, 6 pages, Retrieved April 3, 2012, from PubMed database on the World Wide Web: http://www.pubmed.gov. DOI: 10.1155/2010/218586.

World Health Organization (1996). Health Interview Survey. Towards international harmonization of methods and instruments. Copenhagen: WHO Regional Publications European Series No 58.

AUTHOR'S ADDRESS:

Izabela Tabak

Department of Child and Adolescent Health

Institute of Mother and Child

17a Kasprzaka Street

01-211 Warsaw

Poland

Email: izabela.tabak@imid.med.pl 